\title{
Intranasal insulin influences the olfactory performance of patients with smell loss, dependent on the body mass index: A pilot study*
}

\author{
V. Schöpf ${ }^{1,2,3,}$, K. Kollndorfer ${ }^{1}$, M. Pollak', C.A. Mueller ${ }^{4}$, J. Freiherr ${ }^{5}$ \\ ' Department of Biomedical Imaging and Image-guided Therapy, Medical University of Vienna, Vienna, Austria \\ 2 Department of Psychology, University of Graz, Graz, Austria \\ ${ }^{3}$ BioTechMed, Graz, Austria \\ ${ }^{4}$ Department of Otorhinolaryngology, Medical University of Vienna, Vienna, Austria \\ ${ }^{5}$ Diagnostic and Interventional Neuroradiology, RWTH Aachen University, Aachen, Germany
}

Rhinology 53: 371-378, 2015

DOI:10.4193/Rhino15.065

*Received for publication:

March 16, 2015

Accepted: April 29, 2015

\begin{abstract}
Background: The application of intranasal insulin in healthy humans has been linked to improved memory function, reduced food intake, and increased olfactory thresholds. There has also been some correlation between the morbidities associated with central nervous system (CNS) insulin resistance, such as type II diabetes mellitus, Alzheimer's disease, obesity, and impaired odour recognition. Given that impaired odour recognition is an important component of olfactory performance, mechanisms that govern these effects may account for impaired olfactory functions in anosmic patients.
\end{abstract}

Methodology: Ten patients with post-infectious olfactory loss received intranasal administration of $40 \mathrm{IU}$ insulin or a placebo solution, as well as olfactory performance tests before and after administration.

Results: When administered insulin, patients exhibited an immediate performance improvement with regard to olfactory sensitivity and olfactory intensity ratings. In addition, more odours were correctly identified. Furthermore, an improvement in the odour identification task was detected in patients with higher body mass index.

Conclusion: Results of this pilot study shed light on the link between cerebral insulin level and an impaired sense of smell. This research line might provide a better understanding of olfactory loss in relation to eating and dietary behavior, and could offer opportunities to develop faster therapeutic intervention for patients with olfactory dysfunction.

Key words: anosmia, olfactory dysfunction, metabolic influence, intranasal insulin, smell, olfaction

\section{Introduction}

The sense of smell has been shown to be affected by several neurological diseases (multiple sclerosis, epilepsy) and was proposed to serve as a primary indicator for the occurrence of Alzheimer's and Parkinson's disease (e.g., see $\left.{ }^{(1)}\right)$. Populationbased studies of olfactory loss indicate a prevalence of $22 \%$ between 25-75 years of age (2), 19\% for over 20 years old ${ }^{(3)}$, or $24 \%$ for subjects over 53 years of age ${ }^{(4)}$, with the highest prevalence in older men. The most frequent cause of olfactory loss and dysfunction are infections of the upper respiratory tract, which were most commonly caused by inflammatory diseases of the nose/paranasal sinuses (53\%), respiratory dysfunction (19\%), or postviral conditions $(11 \%){ }^{(5,6)}$. The loss of the sense of smell or functional deficits in olfactory processing are of major concern for healthcare professionals, as these conditions have been associated with reduced quality of life and personal safety in afflicted patients ${ }^{(7)}$. About 79.000 patients are treated for example in Germany for olfactory dysfunction every year (which is an 
average of 46 patients per hospital), the majority of which report of sinunasal diseases as cause for their olfactory loss ${ }^{(6)}$.

Recently, olfactory training was developed presenting a promising therapeutic approach with which to improve olfactory skills in anosmic patients (especially those with post-infectious anosmia ${ }^{(8,9)}$, but also in patients with Parkinson's disease ${ }^{(10)}$. This olfactory training method involves asking anosmics to sample an array of odours several times a day for several weeks. Olfactory training has been proven to increase olfactory performance in anosmics in a randomized, controlled, multicenter study ${ }^{(11)}$. However, this intervention is time-consuming for both patients and caregivers, and requires extensive medical resources. This clearly shows that there is still a dire need to establish treatments that are easy to implement in the patients' daily routine and that are highly cost-effective.

Insulin signaling has been implicated in olfactory function both directly, via receptors expressed on mitral cells in the olfactory bulb ${ }^{(12)}$, and indirectly, via a role in neural protection or regeneration of the olfactory mucosa ${ }^{(13)}$. Insulin receptors are omnipresent in the human brain, including primary olfactory regions like the olfactory bulb ${ }^{(14)}$. Thus far, enhanced central nervous system (CNS) insulin signaling in healthy humans has been linked to improvements in memory functions ${ }^{(15)}$; for review, see $\left.{ }^{(16,17)}\right)$, reduced food intake, and increased olfactory thresholds ${ }^{(18,19)}$. Further, linking odour and memory processing, Brünner et al. recently revealed an odour-cued delayed recall of spatial memories independent of odour type (food or non-food) (20). Given that there is a link between morbidities associated with CNS insulin resistance, such as type II diabetes mellitus, and Alzheimer's disease, obesity, and anorexia nervosa ${ }^{(17,21,22)}$ and impaired odour recognition ${ }^{(23-27)}$, it could be that similar mechanisms may account for impaired olfactory functions in anosmic patients. Further, this provides a strong rationale for hypothesizing that enhanced CNS insulin signaling through intranasal insulin may help to improve olfactory functions in anosmic patients, although there is evidence to the contrary that has been obtained in healthy normosmic adults ${ }^{(18)}$.

The present study aimed to investigate the effects of a single intranasal insulin application in anosmic patients. Previous studies have already found a correlation between body weight, body mass index (BMI), and olfactory performance in different experimental settings ${ }^{(23-25)}$. Furthermore, patients with olfactory loss report alterations of dietary behavior and show a negative correlation of BMI and olfactory function (24). As it is not known whether a causal correlation underlies this interrelation, particular attention was paid to the interaction of body weight, cerebral insulin levels, and olfaction.

\section{Materials and methods}

\section{Experimental protocol}

All subjects were invited to participate in a study consisting of four testing sessions. A schematic description of the test procedures is provided in Figure 1. Throughout the manuscript, we will refer to those four testing sessions as $\mathrm{t} 1$ for the first olfactory performance session and ENT screening, $\mathrm{t} 2$ for intranasal insulin application and olfactory performance test, $\mathrm{t} 3$ for olfactory performance testing, and $\mathrm{t} 4$ for intranasal $\mathrm{NaCl}$ application and olfactory performance testing. The study was conceived and conducted by the investigators at the Medical University of Vienna, who collected and analyzed the data.

\section{Compliance with ethical standards}

The study protocol was approved by the ethics committee of the Medical University of Vienna, Austria (http://www.meduniwien. ac.at/ethik). All experimental procedures were performed in accordance with the Declaration of Helsinki (2003)), including current revisions, the Austrian Arzneimittelgesetz and the EC-GCP guidelines. All participants provided written, informed consent prior to inclusion in the study. All authors warrant the accuracy of the study and the completeness of the data and analysis.

\section{Patients}

Ten anosmic patients with post-infectious olfactory loss (infections of the upper respiratory tract) were included in this study. To determine the cause of olfactory loss, all patients were examined by an ENT, which included an endoscopic examination of the nasal cavity. The patients did not suffer from acute sinunasal diseases and did not take any medication known to interfere with sensory perception. Patients with chronic sinusitis, acute allergic rhinitis, polyposis nasi or any other severe deviation of the nasal cavity were excluded. Furthermore, patients with history of severe head trauma or nasal surgery (e.g. nasal polyps, septoplasty) were not included in our study sample. Sociodemo-

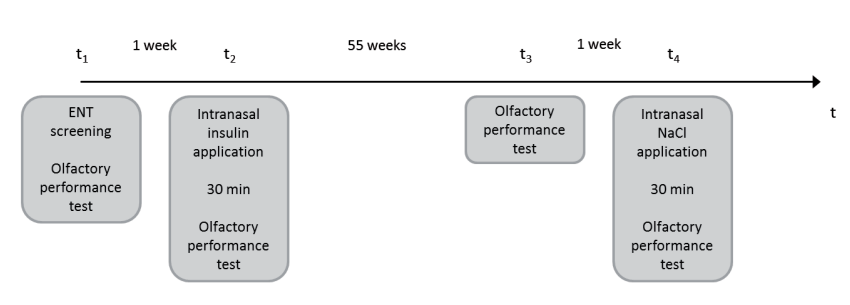

Figure 1. Schematic description of the experimental procedure. Ten anosmic patients were included for measurement time points, $\mathrm{t} 1$ and $\mathrm{t} 2$. Seven of ten agreed to participate for the control conditions, $\mathrm{t} 3$ and $\mathrm{t} 4$. All four testing sessions included the same protocol of olfactory performance tests: assessment of a TDI-score using the Sniffin' sticks test battery, hedonic, and intensity ratings. 
Table 1. Sociodemographic data and olfactory performance score of all patients at the first baseline assessment (t1, see Figure 1).

\begin{tabular}{lc} 
& Patients $(\mathbf{n}=10)$ \\
\hline Age (median, range) & $46.5 \mathrm{yrs}(22-56 \mathrm{yrs})$ \\
$\quad$ Gender (m/f) & $7 / 3$ \\
\hline $\begin{array}{c}\text { Average disease duration } \\
\text { (median, range) }\end{array}$ & $3.5 \mathrm{yrs}(1-30)$ \\
\hline $\begin{array}{c}\text { Average body mass index } \\
\text { (BMl; median, range) }\end{array}$ & $27.15 \mathrm{~kg} / \mathrm{m}^{2}(21.56-36.33)$ \\
$\quad \begin{array}{c}\text { Average TDI score } \\
\text { (median, range) }\end{array}$ & $12.50(10-16.25)$ \\
\hline $\begin{array}{c}\text { Average Threshold score } \\
\text { (median, range) }\end{array}$ & $1.00(1-1.25)$ \\
\hline $\begin{array}{c}\text { Average Discrimination score } \\
\text { (median, range) }\end{array}$ & $7.50(6-9)$ \\
\hline $\begin{array}{c}\text { Average Identification score } \\
\text { (median, range) }\end{array}$ & $4.50(2-7)$ \\
\hline
\end{tabular}

Table 2. Individual data for age, BMI values, disease duration and cause of disease.

\begin{tabular}{|ccccccc|}
\hline ID & $\begin{array}{c}\text { Gen- } \\
\text { der }\end{array}$ & Age & BMI & Cause of disease & $\begin{array}{c}\text { Disease } \\
\text { duration } \\
\text { (in ys) }\end{array}$ \\
\hline 01 & $\mathrm{~m}$ & 42 & 36.33 & $\begin{array}{c}\text { recurrent acute } \\
\text { sinusitis }\end{array}$ & 30.00 \\
\hline 02 & $\mathrm{f}$ & 43 & 23.46 & severe common cold & 1.00 \\
\hline 03 & $\mathrm{f}$ & 45 & 21.56 & acute sinusitis & 8.00 \\
\hline 05 & $\mathrm{~m}$ & 43 & 26.86 & acute sinusitis & 1.50 \\
\hline 06 & $\mathrm{~m}$ & 54 & 29.39 & mild common cold & 4.00 \\
\hline 07 & $\mathrm{~m}$ & 51 & 26.67 & acute rhinitis & 10.00 \\
\hline 08 & $\mathrm{~m}$ & 48 & 27.44 & acute rhinosinusitis & 2.00 \\
\hline 10 & $\mathrm{~m}$ & 22 & 22.31 & severe common cold & 3.00 \\
\hline 09 & 56 & 31.88 & severe common cold & 2.00 \\
\hline
\end{tabular}

graphic data and olfactory performance of all participants are presented in Table 1. Patients had no history of mental illness or head surgery. Individual information on cause of disease is given in Table 2.

\section{Olfactory Performance Test (t1-t4)}

To assess olfactory performance, all subjects were clinically examined to exclude any airway blockages, and subsequently underwent testing using the Sniffin' Sticks test battery (Burghart Instruments, Wedel, Germany). All tests were carried out using a standardized computerized test protocol ${ }^{(28)}$. The original Sniffin' Sticks test includes three subtests that measure nasal chemosensory function using pen-like devices for odour presentation: the odour threshold; odour discrimination; and odour identification tests ${ }^{(29,30)}$. Detection thresholds of $n$-butanol were determined using a single-staircase, three-alternative, forcedchoice (3-AFC) procedure, i.e., subjects were presented with three sticks and had to decide which one contained n-butanol. Odour discrimination was tested using 16 triplets of odorants, again presented as a 3-AFC procedure, i.e., subjects again were presented with three sticks and had to indicate which one smelled differently. The odour identification test consisted of 16 commonly known every day odours and used a multiple-choice answering format with four odours each. This standard olfactory testing procedure was extended by the assessment of odour intensity and hedonics for all odours of the identification test. Therefore, all patients were asked to rate the hedonic valence and intensity of the 16 odours presented during the identification test on a nine-point-scale, with 1 reflecting a pleasant smell/ weak intensity and 9 representing an unpleasant smell/strong intensity. Patients who did not detect an odour during exposure were asked to report "no odour perceived." All olfactory tests were carried out bi-rhinally and results of the subtests were summed to arrive at the so-called TDI score ${ }^{(29,30)}$. Further details about the olfactory performance tests can be found elsewhere $(29,30)$.

Intranasal application (t2, t4)

After ENT screening and the first olfactory performance measurement ( $\mathrm{t} 1$ ), patients received two puffs of liquid insulin per nostril (t2); one puff comprised $0.1 \mathrm{ml}$ insulin, resulting in a total dose of $0.4 \mathrm{ml}$, equaling $40 \mathrm{IU}$ (Actrapid; Novo Nordisk, Mainz, Germany). Olfactory performance measures were accomplished about 30 minutes after application ${ }^{(18)}$, as the insulin level in the cerebrospinal fluid has been shown to peak after this time period ${ }^{(31)}$. Immediately after insulin application, all patients were asked to report any alteration of their sensual perception in the nose. The last food intake took place at least one hour prior to the insulin application. Blood testing was not performed due to the ethical constraints of the local ethics board. Patients were then invited for a third appointment one year (mean, 55 weeks; range, 26-93 weeks) after the intranasal insulin application for olfactory performance testing ( $\mathrm{t} 3$ ), followed by the fourth appointment $(\mathrm{t} 4)$ to receive the placebo condition with two puffs of saline per nostril; one puff comprised $0.1 \mathrm{ml}$ saline, resulting in a total dose of $0.4 \mathrm{ml}$. Ten of 10 patients agreed to participate in the $\mathrm{t} 3$ and $\mathrm{t} 4 \mathrm{measurements.}$ 
Table 3. Individual data for olfactory performance measures in all testing sessions. A minimum of 0 and a maximum of 16 are possible for threshold, discrimination and identification scores. The resulting TDI score thus ranges between 0 and 48 . For each subject increase/decrease/no difference for threshold, discrimination, and identification levels are marked for insulin and sodium chloride application, respectively. For column $\mathrm{t} 2$-t 1 and $\mathrm{t4}$-t3: improvement in olfactory performance is marked with red arrows pointed up, decrease with blue arrows pointed down and no difference with yellow equal signs.

\begin{tabular}{|c|c|c|c|c|c|c|c|c|c|c|c|c|c|c|c|c|c|c|c|c|c|c|}
\hline \multirow{2}{*}{$\begin{array}{l}\text { ID } \\
\text { ID }\end{array}$} & \multicolumn{4}{|c|}{$\mathbf{t}_{1}$ (Baseline 1) } & \multicolumn{4}{|c|}{$t_{2}$ (Insulin) } & \multicolumn{3}{|c|}{$t_{2}-t_{1}$} & \multicolumn{4}{|c|}{$\mathbf{t}_{3}$ (Baseline 2) } & \multicolumn{4}{|c|}{$\mathrm{t}_{4}(\mathrm{NaCl})$} & \multicolumn{3}{|c|}{$t_{4}-t_{3}$} \\
\hline & TDI & $\mathbf{T}$ & D & I & TDI & $\mathbf{T}$ & D & I & $\mathbf{T}$ & D & I & TDI & $\mathbf{T}$ & D & I & TDI & $\mathbf{T}$ & D & I & $\mathbf{T}$ & D & I \\
\hline 01 & 12.00 & 1.00 & 6.00 & 5.00 & 15.25 & 1.25 & 7.00 & 7.00 & $\wedge$ & $\wedge$ & $\wedge$ & 8.50 & 2.50 & 4.00 & 2.00 & 12.25 & 1.25 & 7.00 & 4.00 & v & $\wedge$ & $\wedge$ \\
\hline 02 & 13.00 & 1.00 & 8.00 & 4.00 & 8.25 & 1.25 & 6.00 & 1.00 & $\wedge$ & $v$ & $v$ & 20.00 & 1.00 & 11.00 & 8.00 & 16.25 & 1.25 & 10.00 & 5.00 & $\wedge$ & $v$ & $v$ \\
\hline $03^{*}$ & 7.00 & 1.00 & 2.00 & 4.00 & 12.25 & 2.25 & 8.00 & 2.00 & $\wedge$ & $\wedge$ & $=$ & & & & & & & & & & & \\
\hline $04^{*}$ & 14.25 & 1.25 & 8.00 & 5.00 & 18.00 & 4.00 & 9.00 & 5.00 & $\wedge$ & $\wedge$ & $=$ & & & & & & & & & & & \\
\hline 05 & 14.25 & 1.25 & 7.00 & 6.00 & 19.75 & 6.75 & 6.00 & 7.00 & $\wedge$ & $v$ & $\wedge$ & 19.75 & 5.75 & 6.00 & 8.00 & 21.50 & 5.50 & 12.00 & 4.00 & $v$ & $\wedge$ & $v$ \\
\hline 06 & 10.00 & 1.00 & 6.00 & 3.00 & 13.00 & 1.00 & 8.00 & 4.00 & $=$ & $\wedge$ & $\wedge$ & 8.00 & 1.00 & 3.00 & 4.00 & 10.00 & 1.00 & 7.00 & 2.00 & $=$ & $\wedge$ & $v$ \\
\hline 07 & 16.25 & 1.25 & 8.00 & 7.00 & 11.25 & 1.25 & 7.00 & 3.00 & $=$ & $v$ & $\wedge$ & 13.75 & 2.75 & 6.00 & 5.00 & 14.00 & 1.00 & 7.00 & 6.00 & $v$ & $\wedge$ & $\wedge$ \\
\hline $08^{*}$ & 9.25 & 1.25 & 4.00 & 4.00 & 16.00 & 1.00 & 10.00 & 5.00 & $v$ & $\wedge$ & $\wedge$ & & & & & & & & & & & \\
\hline 09 & 15.00 & 1.00 & 9.00 & 5.00 & 6.00 & 1.00 & 5.00 & 0.00 & $=$ & $=$ & v & 9.50 & 2.50 & 5.00 & 2.00 & 10.25 & 4.25 & 4.00 & 2.00 & $\wedge$ & $v$ & $=$ \\
\hline 10 & 11.00 & 1.00 & 8.00 & 2.00 & 12.25 & 1.25 & 7.00 & 4.00 & $\wedge$ & $v$ & $\wedge$ & 10.00 & 2.00 & 5.00 & 3.00 & 10.00 & 1.00 & 5.00 & 4.00 & $v$ & $=$ & $\wedge$ \\
\hline
\end{tabular}

*These patients did not participate in test sessions $\mathrm{t} 3$ and $\mathrm{t} 4$.

\section{Statistical analysis}

Statistical analyses were performed using the Statistical Package for the Social Sciences (IBM SPSS Statistics 20.0). Due to a violation of normal distribution, data were analyzed using nonparametric tests. To compare the olfactory performance measures at the four testing sessions, a Friedman test was performed. For the comparison of the hedonic and intensity ratings, a Wilcoxon signed-rank test was performed. Correlations were computed using the Spearman's rho $(\rho)$. The alpha level for all statistical tests was set to 0.05 for two-tailed testing.

\section{Results}

In a first step, we compared olfactory measures for intranasal insulin application ( $\mathrm{t} 2$ ) to the first baseline measurement ( $\mathrm{t} 1$ ) by using alteration rates. After intranasal insulin application (t2), 6 of ten patients $(60 \%)$ revealed an improved odour threshold (improved sensitivity, threshold decrease) (mean difference for $\mathrm{t} 1$ and $\mathrm{t} 2$ for all 10 subjects: 1.00 ) and a marginal improvement in the discrimination task (mean difference: 0.70 ). Further, a decline in identification performance was detected (mean difference: -0.70). Detailed individual results are presented in Table 3. In a next step, the four time points were directly compared. Direct comparison for all four time points (t1-t4) for olfactory measures identification, threshold, and discrimination separately, and combined with the TDI score, revealed no significant differences (identification: $p=0.930$; threshold: $p=0.081$; discrimination: $p=0.314$ and TDI score: $p=0.627$ ).

In a third step, we compared olfactory measures for $\mathrm{NaCl}$ application ( $t 4$ ) to the second baseline measurement ( $\mathrm{t} 3$ ) by using alteration rates. After intranasal application of sodium chloride (t4), two of seven patients (28.58\%) achieved a more sensitive odour threshold (mean difference for $\mathrm{t} 3$ and $\mathrm{t} 4$ for all seven participants: -0.32), an improvement in the odour discrimination task (mean difference: 1.71), and a decrease in the odour identification task (mean difference: -0.71 ). Detailed individual results are presented in Table 3.

Next, we compared the results of placebo and insulin conditions, by using alteration rates to correct for differences in baseline measurements comparing $\mathrm{t} 2-\mathrm{t} 1$ for insulin and $\mathrm{t} 4-\mathrm{t} 3$ for placebo. Olfactory measurement values for the differences between the placebo and insulin conditions are depicted in Figure 2 and individual results are presented in Table 3.

Analysis of the intensity ratings revealed that odours were perceived significantly more intensely after insulin compared to placebo administration ( $p=0.043$, Figure 3 ), whereas hedonic ratings did not change significantly (Figure 4). Due to correlations for body weight and body mass index (BMI) and olfactory performance in different experimental settings ${ }^{(23-25)}$, we also investigated whether the BMI could be a predictor for olfactory 

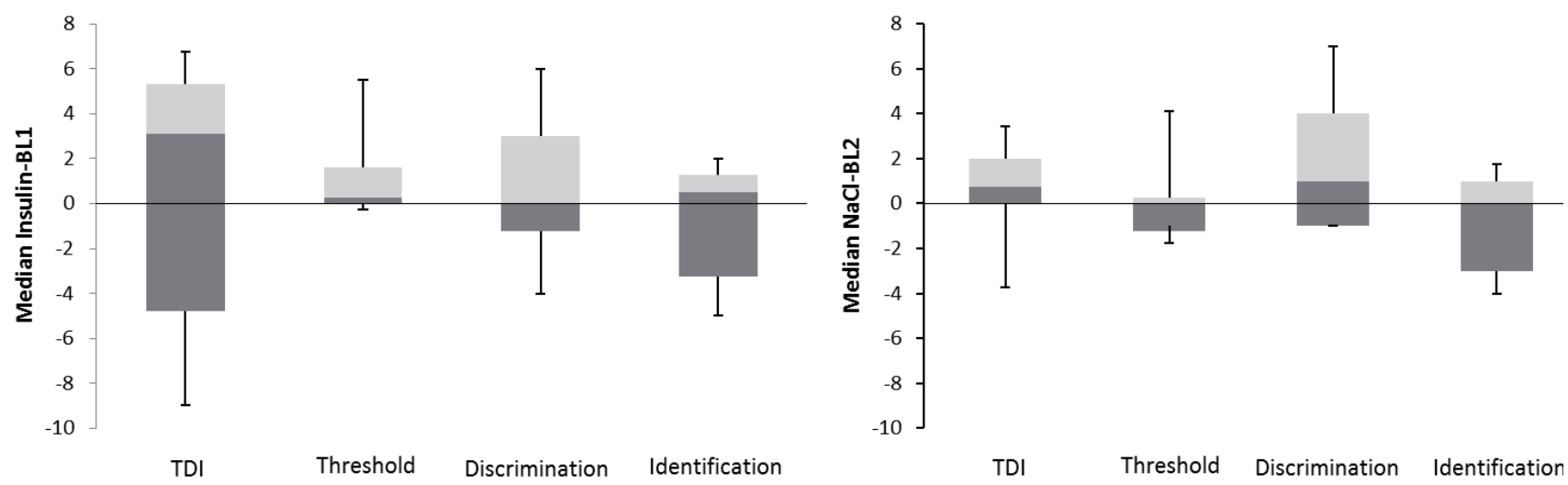

Figure 2. Olfactory performance measures for difference $\mathrm{t} 1$ and $\mathrm{t} 2$ and differences from $\mathrm{t} 3$ and $\mathrm{t} 4$. Due to the small sample size, statistical comparison between the placebo ( $\mathrm{t} 3$ and $\mathrm{t} 4$ ) and insulin ( $\mathrm{t} 1$ and $\mathrm{t} 2$ ) conditions was not possible. This figure visualizes the group-wise effects for the insulin condition compared to the placebo condition: patients' sensitivity was increased after insulin, whereas it was decreased after saline chloride. Medians are marked for all variables.

performance measures in our test setup. Individual measures of BMI are given in Table 2. There was a highly significant correlation between the patient's BMI and the results on the identification task and the TDI score after insulin administration (TDI: $\rho$ $=0.821, p=0.023$; identification: $\rho=0.909, p=0.005$ ). The correlation for the other olfactory performance measures (discrimination and threshold) and BMI were not significant (threshold: $\rho=0.458, p=0.301$; discrimination: $\rho=0.543, p=0.208$ ). The same analysis could not be performed for olfactory performance measures from the placebo application, as only seven patients were included in the placebo measurement.

Due to a broad variety of disease duration in our study sample, a correlation between disease duration and the effect of insulin application on the sense of smell was computed. Individual disease duration can be found in Table 2. No significant correlation was obtained between the duration of olfactory dysfunction and the difference in TDI between $\mathrm{t} 2$ and $\mathrm{t} 1$ (TDI: $\rho=-0.006, \mathrm{p}=$ 0.987; threshold: $\rho=-0.087, p=0.811$; discrimination: $\rho=0.269$, $p=0.452$; identification: $\rho=0.114, p=0.753$ ).

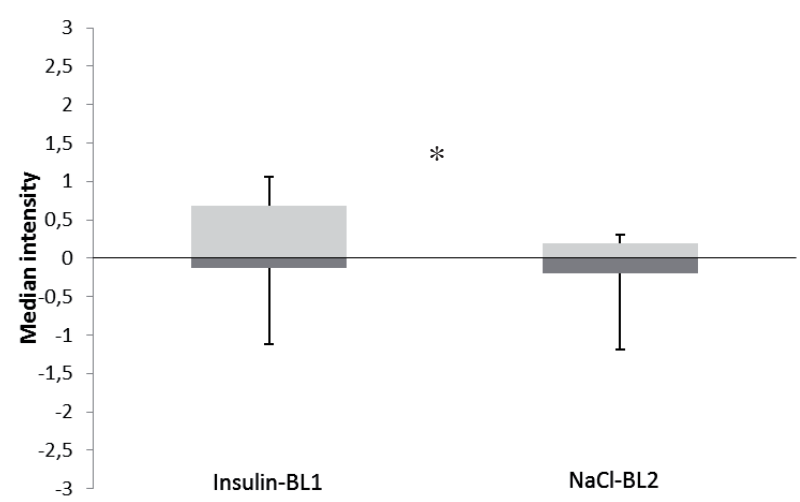

Figure 3. Comparison of intensity ratings of the identification test. Intensity of the 16 odours presented during the identification test was rated on a nine-point-scale, with 1 reflecting weak intensity and nine representing strong intensity. Patients who did not detect an odour during exposure were asked to report "no odour perceived." In the diagram, the comparison of the changes between insulin application at the baseline measurement (t2 vs t1) and saline application at the baseline measurement (t4 vs t3) are shown. Medians are marked for all variables. * statistically significant, $p=0.043$.

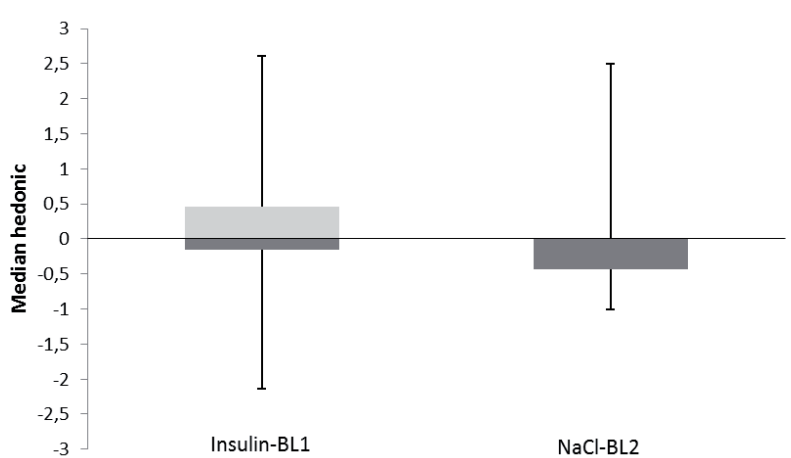

Figure 4. Comparison of hedonic ratings of the identification test. Hedonic ratings of the 16 odours presented during the identification test were acquired on a nine-point-scale, with 1 reflecting a pleasant smell and 9 representing an unpleasant smell. In the diagram, the comparison between the changes in insulin application, compared to that at the baseline measurement (t2 vs $\mathrm{t} 1$ ) and saline application at the baseline measurement ( $\mathrm{t} 4 \mathrm{vs} \mathrm{t} 3$ ), are shown. Medians are marked for all variables. 


\section{Discussion}

This clinical pilot study involved the investigation of intranasal insulin on olfactory performance measures in patients with anosmia. Sixty percent of the patients who were administered insulin exhibited an immediate performance increase with regard to olfactory sensitivity, and subjective intensity ratings of odours increased significantly. A descriptive analysis of the individual ratings also showed that identification scores decreased after insulin administration. This might seem controversial because patients exhibited an improvement in sensitivity, yet also showed a decrease of identification and discrimination ratings. However, this can be explained by the differing degree of task difficulty. Further, odour sensitivity has been reported to be a more peripheral measure of olfactory processing, while odour identification and discrimination are rendered as more central and part of the higher cognitive olfactory processes ${ }^{(32)}$. It is possible that the diverse processing steps are differentially influenced by an intranasal insulin application. This might be linked to long disease durations that result in difficulties of naming and discrimination of smells due to excessive demands of odorous impressions in the clinical test battery. Disease duration, however, had no influence on the effect of intranasal insulin on olfactory performance in our sample.

Our results are contradictory in comparison to existing studies in healthy humans ${ }^{(18,19)}$ in whom an application of intranasal insulin evoked a decrease of olfactory sensitivity in comparison to the placebo condition. Of course, we cannot be sure whether this effect was attributable to the small number of patients who came back for the placebo testing. One explanation for our finding could be a "floor effect" within the impaired olfactory system. In other words, patients already had such a low olfactory sensitivity during the baseline measurement that a negative effect of insulin cannot be measured using this method of evaluation. Especially in the mouse model, olfactory performance measures have been extensively investigated and are known to be influenced on a metabolic level by various molecules, such as ghrelin, insulin, and leptin, which are the modulators responsible for regular cycles of food intake ${ }^{(33)}$. These findings correspond to the effect discovered in this pilot study, which was the relationship between BMI and odour identification ability, post intranasal insulin application, which was highly significant. We found that the higher the BMI was, the better patients performed in the identification task immediately after insulin application, and this was not the case for the saline application.

The ability of intranasal insulin to bypass the blood-brain-barrier has already been discovered ${ }^{(34)}$. Insulin is extracellularly transported by the axons of the olfactory nerve through the lamina cribrosa to reach the olfactory bulb and is then distributed to other brain areas. This process enables an increase of insulin levels in the cerebrospinal fluid in as little as 20 to 30 minutes after intranasal application ${ }^{(17)}$. It is known that insulin receptors of the CNS play an important role in signal transduction and processing, such as processing of emotions, working memory, language, ingestion, and chemosensory perception. Therefore, insulin receptor densities and receptors of the insulin-likegrowth-factors (IGF) are higher in specific areas, including the frontal cortex, the hippocampus, and the amygdala (17). Patients with pre-obesity and obesity suffer from insulin homeostasis changes. The lack of insulin manifests as a reduced sensitivity of the insulin receptor-so-called insulin resistance-which is correlated with serine phosphorylation of the insulin-receptorsubstrate-1 (IRS-1pSer) with the consequent decreased signal transduction and a quantitatively decreased insulin receptor. This effect also manifests in pre-diabetic metabolism, as well as in type II diabetes. These central changes of insulin metabolism can even be assessed as reduced theta activity, using EEG (17). Patients with type II diabetes also suffer from decreased olfactory function (27). These mechanisms plausibly contribute to a BMI-correlated effect of odour identification ability. It has been reported that the ability to correctly identify odours has been both positively ${ }^{(35)}$ and negatively ${ }^{(36)}$ correlated with $\mathrm{BMI}$ in subjects older than 65. Also, morbidly obese patients show decreased olfactory acuity and are significantly more likely to develop anosmia ${ }^{(37,38)}$. These and other studies collectively appear to indicate that obesity increases the detection threshold of odours, while severe obesity increases the risk for anosmia ${ }^{(33)}$. A limiting factor of this study is the small sample size, the small body weight range, and non-randomized testing. Due to the small sample size, statistical testing was not valid in most cases, and only a description of the individual test measures was possible. Future investigation should therefore focus on the effect duration and reproducibility within subjects. In the presented study, patients were instructed not to eat one hour prior to the testing session and the time between the last food intake and the testing session, as well as a subjective hunger/satiety rating, were recorded. Although both variables were not correlated with the effects of insulin administration on olfactory performance, future studies should investigate the interaction effect of insulin administration and smell performance levels with regard to fasting in anosmics. Due to the results of the presented study, further investigation of patients with olfactory dysfunction (mild and strong hyposmia, anosmia) with a broader BMI range will be required to clarify the effect of insulin on olfactory performance. A future challenge will be to investigate the mechanisms behind the correspondence of nutritional and metabolic states in relation to olfactory function. As smell is an important component in food intake and regulation, investigations about how internal and external metabolic signals could modulate these measures are needed. 
With regard to future forms of therapy for olfactory dysfunction, the question arises of how olfactory memory performance might be affected by intranasal insulin in patients with olfactory dysfunction. As olfactory awareness is positively associated with odour memory ${ }^{(39)}$, and odour memory is influenced by intranasal insulin application ${ }^{(20)}$, this might be a promising area of investigation.

\section{Acknowledgement}

The authors thank Elisabeth Hoche, Ksenia Kowalczyk, Iris Ohrenberger, and Jacqueline Krajnik for assistance with olfactory performance measurements. KK is supported by the FWF granted to VS (P23205-B09). JF is funded by START funding from the Medical Faculty of RWTH Aachen University (169/11) and the DFG (FR 3114/6-1). We would further like to thank Aero Pump for providing us with spray bottles to perform this experiment.

\section{Author contributions}

VS, KK, JK designed the experiment and performed the analysis. VS, KK, MP, CAM collected the data. VS, KK, MP, CAM, JK wrote the paper.

\section{Conflict of interest}

The authors declare no conflict of interest.

\section{References}

1. Barresi M, Ciurleo R, Giacoppo S, et al. Evaluation of olfactory dysfunction in neurodegenerative diseases. J Neurol Sci. 2012; 323: 16-24.

2. Vennemann MM, Hummel T, Berger K. The association between smoking and smell and taste impairment in the general population. J Neurol. 2008; 255: 1121-1126.

3. Brämerson A, Johansson L, Ek L, Nordin S, Bende M. Prevalence of olfactory dysfunction: the skövde population-based study Laryngoscope. 2004; 114: 733-737.

4. Murphy C, Schubert CR, Cruickshanks KJ, Klein BEK, Klein R, Nondahl DM. Prevalence of olfactory impairment in older adults. JAMA. 2002; 288: 2307-2312.

5. Deems DA, Doty RL, Settle RG, et al. Smell and taste disorders, a study of 750 patients from the University of Pennsylvania Smell and Taste Center. Arch Otolaryngol Head Neck Surg. 1991; 117: 519-528.

6. Damm M, Temmel A, Welge-Lüssen A, et al. [Olfactory dysfunctions. Epidemiology and therapy in Germany, Austria and Switzerland]. HNO. 2004; 52: 112-120.

7. Croy I, Nordin S, Hummel T. Olfactory Disorders and Quality of Life - An Updated Review. Chem Senses. 2014; 39: 185-194.

8. Hummel T, Rissom K, Reden J, Hähner A, Weidenbecher $M$, Hüttenbrink K. Effects of olfactory training in patients with olfactory loss. Laryngoscope. 2009; 119: 496-499.

9. Damm M, Pikart LK, Reimann H, et al. Olfactory training is helpful in postinfectious olfactory loss: A randomized, controlled, multicenter study. Laryngoscope. 2014; 124: 826-831.

10. Haehner A, Tosch C, Wolz M, et al. Olfactory training in patients with Parkinson's disease. PLoS One. 2013; 8 (4): e61680.

11. Damm M, Pikart LK, Reimann H, et al. Olfactory training is helpful in postinfectious olfactory loss: A randomized, controlled, multicenter study. Laryngoscope. 2014; 124: 826-831.

12. Fadool DA, Tucker K, Pedarzani P. Mitral cells of the olfactory bulb perform metabolic sensing and are disrupted by obesity at the level of the Kv1.3 ion channel. PLoS One.
2011; 6(9): e24921.

13. Lacroix M-C, Rodriguez-Enfedaque $A$, Grébert D, et al. Insulin but not leptin protects olfactory mucosa from apoptosis. J Neuroendocrinol. 2011; 23: 627-640.

14. Havrankova J, Roth J, Brownstein M. Insulin receptors are widely distributed in the central nervous system of the rat. Nature. 1978; 272: 827-829.

15. Benedict C, Hallschmid M, Hatke A, et al. Intranasal insulin improves memory in humans. Psychoneuroendocrinology. 2004; 29: 1326-1334.

16. Brünner YF, Benedict C, Freiherr J. [Targeting the brain through the nose. Effects of intranasally administered insulin]. Nervenarzt. 2013; 84: 949-954.

17. Freiherr J, Hallschmid M, Frey WH, et al. Intranasal insulin as a treatment for Alzheimer's disease: a review of basic research and clinical evidence. CNS Drugs. 2013; 27: 505-514.

18. Brünner YF, Benedict C, Freiherr J. Intranasal insulin reduces olfactory sensitivity in normosmic humans. J Clin Endocrinol Metab. 2013; 98: E1626-1630.

19. Ketterer C, Heni M, Thamer C, HerzbergSchäfer SA, Häring H-U, Fritsche A. Acute, short-term hyperinsulinemia increases olfactory threshold in healthy subjects. Int J Obes (Lond). 2011; 35: 1135-1138.

20. Brünner $Y$, Kofoet $A$, Benedict C, Freiherr J. Central insulin administration improves odor-cued reactivation of spatial memory in young men. J Clin Endocrinol Metab. 2015; 100: 212-219.

21. Tschritter O, Preissl H, Hennige AM, et al. The cerebrocortical response to hyperinsulinemia is reduced in overweight humans: a magnetoencephalographic study. Proc Natl Acad Sci U S A. 2006; 103: 12103-12108.

22. Hallschmid M, Benedict C, Schultes B, Born J, Kern W. Obese men respond to cognitive but not to catabolic brain insulin signaling. Int J Obes (Lond). 2008; 32: 275-282.

23. Aschenbrenner $K$, Scholze $N$, Joraschky $P_{\text {, }}$ Hummel T. Gustatory and olfactory sensitivity in patients with anorexia and bulimia in the course of treatment. J Psychiatr Res. 2008; 43: 129-137
24. Aschenbrenner K, Hummel C, Teszmer K, et al. The influence of olfactory loss on dietary behaviors. Laryngoscope. 2008; 118: 135144.

25. Schreder T, Albrecht J, Kleemann AM, et al. Olfactory performance of patients with anorexia nervosa and healthy subjects in hunger and satiety. Rhinology. 2008; 46: 175-183.

26. Patterson DS, Turner P, Smart J V. Smell threshold in diabetes mellitus. Nature. 1966; 209: 625

27. Le Floch JP, Le Lièvre G, Labroue M, Paul M, Peynegre R, Perlemuter L. Smell dysfunction and related factors in diabetic patients. Diabetes Care. 1993; 16: 934-937.

28. Hummel C, Zucco GM, lannilli E, Maboshe W, Landis BN, Hummel T. OLAF: standardization of international olfactory tests. Eur Arch Oto-Rhino-Laryngology. Springer-Verlag; 2012; 269: 871-880.

29. Kobal G, Hummel T, Sekinger B, Barz S, Roscher S, Wolf S. 'Sniffin' sticks': screening of olfactory performance. Rhinology. 1996; 34: 222-226.

30. Hummel T, Sekinger B, Wolf SR, Pauli E, Kobal G. 'Sniffin' sticks': olfactory performance assessed by the combined testing of odor identification, odor discrimination and olfactory threshold. Chem Senses. 1997; 22: 39-52.

31. Born J, Lange T, Kern W, McGregor GP, Bickel U, Fehm HL. Sniffing neuropeptides: a transnasal approach to the human brain. Nat Neurosci. 2002; 5: 514-516.

32. Hedner M, Larsson M, Arnold N, Zucco GM, Hummel T. Cognitive factors in odor detection, odor discrimination, and odor identification tasks. J Clin Exp Neuropsychol. 2010; 32: 1062-1067.

33. Palouzier-Paulignan $B$, Lacroix M-C, Aimé $P$, et al. Olfaction under metabolic influences. Chem Senses. 2012; 37: 769-797.

34. Duan X, Mao S. New strategies to improve the intranasal absorption of insulin. Drug Discov Today. 2010; 15: 416-427.

35. Simchen U, Koebnick C, Hoyer S, Issanchou S, Zunft H-JF. Odour and taste sensitivity is associated with body weight and extent of misreporting of body weight. Eur J Clin 
Nutr. 2006; 60: 698-705

36. Hunter-Smith DG, Kessel K, Grant M Piotrowski ZH. Association between elevated body-mass index and impaired sense of smell in older people. J Am Geriatr Soc. 1996; 44: 100-101.

37. Richardson BE, Vander Woude EA, Sudan R, Thompson JS, Leopold DA. Altered olfactory acuity in the morbidly obese. Obes Surg. 2004; 14: 967-969.

38. Richardson BE, Vanderwoude EA, Sudan R,
Leopold DA, Thompson JS. Gastric bypass does not influence olfactory function in obese patients. Obes Surg. 2012; 22: 283286.

39. Arshamian A, Willander J, Larsson M. Olfactory awareness is positively associated to odour memory. J Cogn Psychol. Routledge; 2011; 23: 220-226.
Veronika Schöpf

Universitätsplatz 2

A-8010 Graz

Austria

Tel: $+43-316-3808490$

E-mail: veronika.schoepf@uni-graz.at

\section{ANNOUNCEMENT}

\section{ERS-FELLOWSHIPS 2016}

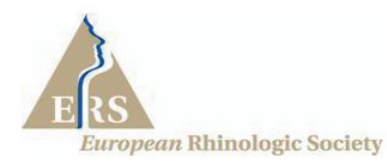

Sponsored by

\section{THE EUROPEAN RHINOLOGIC SOCIETY}

Available to ERS-members

One place available on each of the following Courses in 2016

13th International Course in advanced Sinus Surgery

Amsterdam, The Netherlands, March 9-11, 2016

Course Director: Prof. Dr. W.J. Fokkens

Fax: +31205669573

Tel: + 31205668586

Email: m.b.vanhuiden@amc.uva.nl

\section{2nd International Graz Course on Rhinosurgery}

Graz, Austria, July, 2016

Course Director: Prof. Dr. H. Stammberger

Email: claire.zwerina@meduni-graz.at

23th Rhinoplasty Course (International Course in Modern

Rhinoplasty Techniques)

Amsterdam, The Netherlands, October 2016

Course Director: Peter W Hellings, MD, PhD

Tel: +31 205668586

Fax: +31205669573

Email: m.b.vanhuiden@amc.uva.nl

Website: www.rhinoplastycourse.nl $17^{\text {th }}$ International Course on Reconstructive and Aesthetic Surgery of the Nose and Face "Around the Nose" Nijmegen, The Netherlands, June 15-17, 2016 Tel: +31 243619671

Email: Y.Savelkoul-Broekman@pao.umen.nl Website www.paoheyendael.nl

\section{Endoscopic approach to Rhinosinusitis in Sinonasal Disease} London, United Kingdom, October 2016

Course Directors: Prof. V.J. Lund

Tel: +44 2076798909

Fax: +44 2078379279

Email: a.kelly@ulc.ac.uk

Website www.ucl.ac.uk/ear/training/short-courses

Sponsorship comprises a sum of 1200 Euro to assist in both registration fees and costs of accommodation/travelling. More information and application forms are available on the website:

Every year, a number of Fellowships are awarded each to the value of $€ 1200$ to enable trainees to attend one of a range of international courses.

Applicants must complete an application form and return it electronically to the secretary: rhinologysecretary@amc.nl by the 15 th January 2016 irrespective of the course for which they are applying.

The applicant must be 35 or under and must be a junior member of ERS

Applicants may apply for more than one course but can only be awarded one place so should indicate an order of preference if they are applying for more than one course.

The application must be accompanied by a letter of support from their head of department and/or other supporting evidence indicating why they should be awarded the fellowship. This should cover their stage of training, aptitude and knowledge.

Then the reports as presently shown followed by the updated info on the courses.

For more information see www.europeanrhinologicsociety.org or www.rhinologyjournal.com 